\title{
Narrativas Multimodais: a imagem dos matemáticos em performances matemáticas digitais
}

\author{
Multimodal Narratives: the image of mathematicians in digital \\ mathematical performances
}

\author{
Ricardo Scucuglia Rodrigues da Silva*
}

\begin{abstract}
Resumo
Neste artigo apresento um estudo no qual investiguei as imagens sobre matemáticos em um contexto no qual estudantes de graduação foram engajados na produção de performances matemáticas digitais (PMD). Argumento que PMD podem ser concebidas como narrativas multimodais nas quais são comunicadas ideias matemáticas através das artes. A partir da realização de um curso de extensão universitária, os estudantes produziram duas PMD sob minha orientação, sendo uma de natureza cinematográfica e outra musical. Ao buscar uma fundamentação metodológica baseada na noção de estudo de caso qualitativo, destaco que doze imagens sobre os matemáticos foram construídas neste estudo. Explorando o caráter narrativo emergente com a atividade performática na comunicação de ideias matemáticas foi possível discutir relações entre narrativa, paramatemática e identidade. Este estudo oferece meios para a desconstrução de imagens estereotipadas sobre a Matemática e os matemáticos e fomenta a construção de imagens alternativas nos cenários educacionais e sociais enfatizando as artes e o uso de tecnologias digitais.
\end{abstract}

Palavras-chave: Educação Matemática. Vídeos. Artes. Multimodalidade. Tecnologias Digitais.

\begin{abstract}
In this paper I present a case study. I investigated the images of mathematicians in a context in which undergraduate students were engaged in the production of digital mathematical performances (DMP). I argue that DMP may be conceptualized as multimodal narratives in which one communicates mathematical ideas using the arts. The students were enrolled in an extra-class course and produced two DMP under my supervision: a dramatic one and a musical one. Twelve different images of mathematicians were explored in the DMP. In my discussions, I highlight the narrative nature emergent from performance and the relation involving narrative, paramathematics, and identity. This research offers ways to deconstruct stereotypes about mathematics and mathematicians and supports the construction of alternate public images through the production of multimodal narratives based on the use of arts and digital technology.
\end{abstract}

Key-words: Mathematics Education. Videos. Arts; Multimodality. Digital Technology.

\footnotetext{
" Doutor em Education Studies pela Universidade de Western Ontario (UWO). Professor Assistento no Departamento de Educação da Universidade Estadual Paulista (UNESP), Campus de São José do Rio Preto, SP, Brasil. Endereço para correspondência: Rua Cristóvão Colombo, 2265, Jardim Nazareth, CEP 15054-000, São José do Rio Preto, SP. E-mail: ricardos@ibilce.unesp.br.
} 


\section{Inquietações iniciais}

Pesquisas em Educação Matemática tem investigado diferentes problemáticas relacionadas à imagem pública da matemática e dos matemáticos (PICKER; BERRY, 2000). Estes estudos oferecem indícios sobre o fato de que muitas das experiências matemáticas escolares vividas pelos estudantes durante a Educação básica originaram e fomentam a construção de imagens negativas, reducionistas e estereotipadas sobre a Matemática e os matemáticos (GADANIDIS, 2012). Diante dessa inquietação desenvolvi uma pesquisa na qual investiguei aspectos sobre a imagem pública dos matemáticos em um cenário fomentado pela produção de performances matemáticas digitais (PMD) ${ }^{1}$. Dentre das questões investigadas no estudo, discuto neste artigo aspectos relacionados às seguintes perguntas: Que tipo de imagens sobre os matemáticos são construídas através da produção de PMD? Como analisar as PMD produzidas enquanto narrativas multimodais?

\subsection{A Metáfora dos Vogons}

Metaforicamente, muitos estudantes vêem uma aula de matemática como o recital de poesias dos Vogons no filme $O$ Guia do Mochileiro das Galáxias (ADAMS, 2005). Os Vogons são um povo extraterreste conhecido por sua inteligência, aparência monstruosa, brutalidade e, principalmente, inaptidão como poetas. A poesia dos Vogons é considerada a terceira pior do universo, então, ao viajarem através das galáxias, eles sequestram seres de outros planetas e os aprisionam. Somente assim os Vogons têm público em seus recitais de poesia, geralmente realizadas como meio de tortura para confissões, convencimento, chantagem e submissão dos prisioneiros (Figura 1).

\footnotetext{
1 Algumas ideias apresentadas neste artigo foram discutidas em outros dois artigos publicados em anais de congressos no ano de 2013 (XI ENEM e VI CIEM).
} 


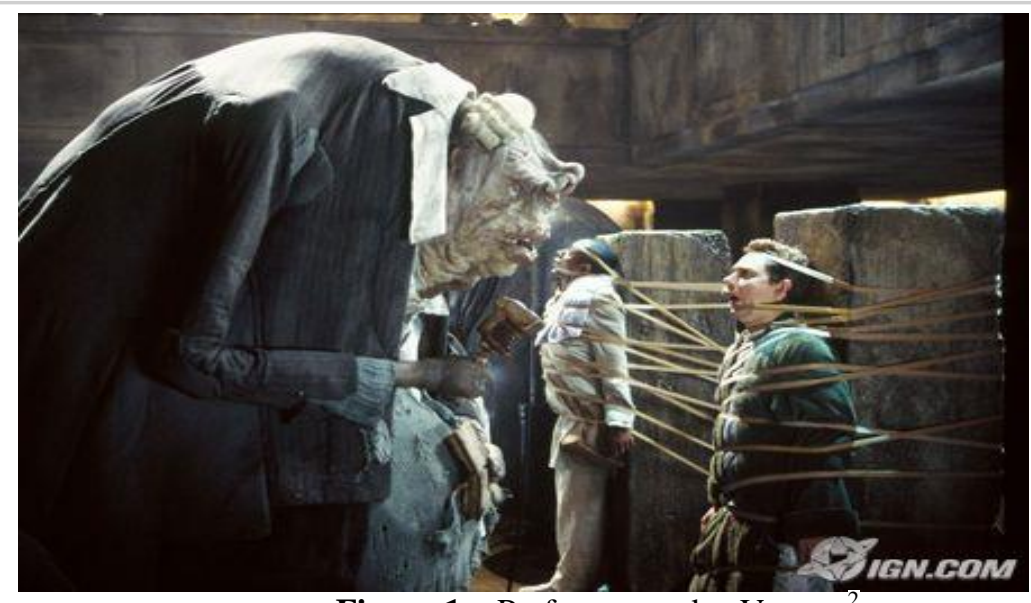

Figura 1 - Performance dos Vogons ${ }^{2}$

A metáfora dos Vogons oferece meios para expor algumas inquietações iniciais:

(1) Encontrar uma pessoa que ame e tenha desejo pela Matemática ou prazer em frequentar aulas de Matemática é um caso raro (GADANIDIS, 2012).

a. Por que os estudantes não veem a beleza e as maravilhas da Matemática?

b. Como e por que a Matemática da Educação Básica se transformou em um tipo de poesia Vogon e as aulas em recitais dos Vogons?

c. Que ideias matemáticas e atividades pedagógicas propulsionariam um cenário alternativo que desconstrói a imagem dos Vogons?

(2) Os estudantes veem os matemáticos apenas como o professor de matemática, associando-os a pouquíssimas boas qualidades e muitas características negativas.

a. O professor de Matemática é visto como um Vogon: inteligente, mas assustador, mal-humorado, intimidador e insensível.

b. O que ele diz não faz sentido para o estudante ("linguagem extraterrestre").

c. Como construir uma imagem alternativa sobre os matemáticos na educação básica e na sociedade? Quais seriam estas imagens?

\section{A imagem pública da Matemática e dos matemáticos}

A imagem da matemática é um tema investigado e discutido em Educação Matemática (FRANK, 1990; SPANGLER, 1992; FURINGHETTI, 1993; LIM, 1999)³.

2 Fonte da imagem: http://moviesmedia.ign.com/hhgttg/image/article/586/586626/hitchhikers-guide-to-thegalaxy-the-20050209041404556.jpg.

${ }^{3} \mathrm{O}$ termo imagem da matemática está sendo concebido de forma ampla no presente estudo: "inclui todas as representações visuais e verbais, imagens metafóricas e associações, crenças, atitudes e sentimentos relacionados à matemática e experiências de aprendizagem de matemática" (LIM, 1999, p. 2). 
De acordo com Lim e Ernest (2001), os discursos predominantes encontrados nos diversificados ambientes sociais explicitam uma concepção filosoficamente limitada acerca dos fundamentos e da natureza do conhecimento matemático. A imagem pública da Matemática é fundamentalmente caracterizada por aspectos reducionistas relacionados apenas às tendências formalista e absolutista da filosofia da Matemática (LIM, 1999).

Raramente são encontradas nos cenários sociais imagens que explicitem uma concepção falibilista ou de incompletude sobre a Matemática. Esta visão estereotipada e filosoficamente singular sobre a Matemática fomenta a ideologia da certeza: imagem na qual a Matemática é vista como exata, lógica, perfeita, pura, absolutamente verdadeira, única, soberana e inquestionável (BORBA; SKOVSMOSE, 2001) ${ }^{4}$.

De acordo com Furinghetti (1993), as mídias tendem a perpetuar tanto a ideologia da certeza como as qualidades negativas frequentemente atribuídas pelos indivíduos à Matemática ou ao estudo da Matemática. No cinema, na literatura ou no jornalismo, a Matemática é mostrada como uma ciência ou disciplina importante, mas fria, não humana, difícil, chata, assustadora, detestável e elitista. Embora existam diversas narrativas disseminadas nos meios de comunicação que abordem temas interessantes como papel social da matemática financeira, a matemática na natureza, matemática e música e fractais, raramente os filmes, livros didáticos e literários, programas de televisão, telejornais, revistas em quadrinho ou conteúdos da Internet constroem uma imagem da Matemática como linda, maravilhosa, divertida, desejada, amada, prazerosa, plural e incerta (GADANIDIS, 2012).

A imagem pública dos matemáticos é também um tema de investigação Educação Matemática (PICKER; BERRY, 2001; RENSSA, 2006; GADANIDIS, 2012).

De acordo com Picker e Berry (2000), as pesquisas que investigam imagens de estudantes sobre os matemáticos podem oferecer meios para que professores compreendam algumas concepções e atitudes dos estudantes com relação à Matemática e ao processo de aprendizagem em sala de aula. Essas investigações podem contribuir para reflexão sobre a prática docente e oferecem meios para uma possível transformação didático-pedagógica.

\footnotetext{
${ }^{4}$ Borba e Skovsmose (2004) discutem situações nas quais o uso da Matemática não implica necessariamente em justiça social. Pelo contrário, a Matemática é frequentemente utilizada de forma estratégica pelas classes dominantes, de modo a garantir interesses econômicos e políticos particulares ou de grupos específicos. Não deve ser uma surpresa o fato de uma imagem de incerteza sobre a Matemática ser subversiva ao status quo. $\mathrm{O}$ posicionamento crítico frente ao conhecimento matemático na legitimação de verdades e estabelecimento de relações de poder enfraquecem os instrumentos de controle social.
} 
Rock e Shaw (2000) realizaram uma pesquisa com estudantes dos Anos Iniciais e Finais do Ensino Fundamental. Para investigar os tipos de imagens que as crianças têm sobre os matemáticos, os pesquisadores solicitaram aos estudantes que respondessem um questionário online que abordava dois aspectos principais: (i) Problemas que os matemáticos resolvem; (ii) Instrumentos ou tecnologias que utilizam para trabalhar. Como resultado, Rock e Shaw (2000) comentam que o matemático é predominantemente visto pelos estudantes como sendo o(a) professor(a) de Matemática, caracterizado como o profissional que: (a) resolve muitas expressões numéricas "difíceis” com facilidade e (b) utiliza livros, lápis e papel, giz e lousa e calculadoras em suas atividades profissionais.

Em outro estudo, Picker e Berry (2001) investigaram as imagens de estudantes (12-13 anos de idade) sobre os matemáticos em uma pesquisa realizada em cinco países diferentes. Com base na análise de aproximadamente 500 desenhos de estudantes, Picker e Berry (2001) argumentam que, mesmo dentre a diversidade cultural, as imagens sobre os matemáticos são bastante comuns. Como proposta voltada à superação de alguns estereótipos, os autores sugerem que professores convidem matemáticos profissionais para dialogar em salas de aula da Educação Básica, de modo a explicitar a pluralidade que caracteriza o local de trabalho, as atividades profissionais e os instrumentos usados pelos matemáticos. A realização de pesquisas em bibliotecas e na Internet também é apontada como alternativa.

Na pesquisa realizada por Reensa (2006), com base em questionários respondidos por indivíduos presentes em locais públicos, a autora comenta que as expressões geralmente utilizadas para descrever algo marcante sobre a identidade de um matemático são: nerd, louco, antissocial, obeso, quatro olhos (uso de lentes corretivas), brega (mal vestido), desastrado, estressado e nervoso, arrogante e sarcástico, dentre outras. Estes estereótipos sobre os matemáticos são reproduzidos pelas mídias, que ainda destacam a imagem na qual a atividade profissional em Matemática é predominantemente masculina.

De acordo com Gadanidis e Scucuglia (2010), a utilização das artes e das mídias digitais pode contribuir para que estudantes e professores desconstruam estereótipos sobre a Matemática e sobre os matemáticos e construam imagens alternativas. Na proposta dos autores, engajar a comunidade escolar (estudantes, pais, professores) na produção de performances matemáticas digitais oferece meios para que a imagem pública da Matemática adquira complexidade matemática, pluralidade filosófica, relevância social e diversidade cultural. Concomitantemente, a imagem dos matemáticos pode ser transformada quando a atividade matemática é exercida enquanto uma experiência humana, artística, prazerosa, 
colaborativa e educacional. É possível explorar possibilidades alternativas com relação ao pensamento matemático a partir da música, do cinema, da produção de narrativas digitais e da disseminação de narrativas audiovisuais na Internet (SCUCUGLIA; GADANIDIS, 2013).

\section{Performance matemática digital}

A noção de performance matemática digital (PMD) foi originalmente proposta em um projeto de pesquisa voltado à inovação tecnológica e educacional. Uma concepção inicial sobre PMD pode ser descrita como: a comunicação de ideias matemática através das artes (performáticas) e das mídias digitais (GADANIDIS; BORBA, 2008).

Desde 2006 diversos tipos de atividades de ensino, pesquisa e extensão sobre PMD têm sido desenvolvidas colaborativamente com a realização de projetos fomentados por instituições diversas. O locus de presença dos estudos sobre PMD na literatura acadêmica e a natureza das discussões sobre esses estudos são indícios para se considerar que PMD vem ganhando projeção acadêmica-educacional e se consolidando como linha de pesquisa e possível tendência em Educação Matemática (GADANIDIS; BORBA, 2008, GADANIDIS; GEIGER, 2010; SCUCUGLIA, 2012; SCUCUGLIA; GADANIDIS, 2013).

O tipo mais comum de PMD tem sido produzido em formato audiovisual (vídeo digital). Uma vez que o uso de equipamentos eletrônicos digitais como câmeras de vídeo e telefones celulares e o acesso a Internet (Web 2.0) tornaram a produção e o compartilhamento online de vídeos plenamente viáveis, a presença de PMD tem se popularizado tanto em redes sociais (YouTube e Facebook) como fomentado a formação de comunidades que interagem em ambientes educacionais online como o Math + Science Performance Festival ${ }^{5}$.

Ao engajar estudantes na produção de PMD, eu busco constituir um ambiente multimodal de aprendizagem (WALSH, 2011) no qual existem recursos e processos específicos disponíveis (atividades investigativas, produção audiovisual, etc.) e há um contexto e uma proposta social e pedagógica como pano de fundo.

No âmbito deste estudo ${ }^{6}$ as propostas visam:

\footnotetext{
${ }^{5}$ Ver www.mathfest.ca

${ }^{6}$ Pesquisa de Pós-Doutorado realizada junto ao Grupo de Pesquisa em Informática, Mídias e Educação Matemática (GPIMEM) - Universidade Estadual Paulista (UNESP), Campus Rio Claro. Projeto financiado pelo CNPq. Processo: 158000/2012-9. Orientador: Dr. Marcelo C. Borba.
} 
(i) Explorar ideias matemáticas através das artes; ideias com múltiplas formas de complexidade investigativa que ofereçam meios para desconstruir estereótipos formalistas e que possam ser exploradas em variados níveis de ensino (e.g., conceito de limite - séries infinitas);

(ii) Explorar e construir imagens alternativas sobre os matemáticos;

(iii) Produzir PMD envolvendo (i) e (ii), trazendo ao contexto social extraescolar (redes sociais da Internet) e através de narrativas multimodais imagens alternativas sobre a Matemática e os matemáticos, e que podem ter uma função didático-pedagógica transformativa voltada à inovação educacional.

\section{Cenário metodológico}

Como mencionado no anteriormente, neste artigo discuto aspectos concernentes a um estudo no qual investiguei a imagem pública da Matemática e dos matemáticos em um contexto no qual estudantes de graduação foram engajados na produção de PMD. Especificamente, questionei:

(a) Como estudantes produzem PMD enfocando a imagem pública do matemático?

(b) Que tipos de imagens sobre matemáticos são construídos?

(c) Qual a natureza conceitual das PMD produzidas?

\subsection{Estudo de casos}

A principal perspectiva metodológica que orienta este artigo é a noção de estudo de caso qualitativo (STAKE, 2003). Como mencionado em artigos anteriores ${ }^{7}$, Stake (2003) argumenta que estudos de casos são específicos e limitados, têm padrões ou singularidades e o foco está na compreensão da complexidade do caso."Os estudos de caso permitem refinar a teoria e sugerir complexidade para a investigação" (STAKE, 2003, p. 156).

Segundo Yin (2006, p. 111), a relevância do "método de estudo de caso é a sua capacidade em oferecer meios para analisar, em profundidade, um caso, dentro de seu contexto de vida real". De acordo com esse autor, estudo de caso é bem aplicado quando a

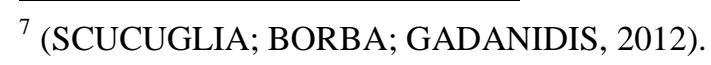


pesquisa aborda questões descritivas e exploratórias, que tem como objetivo produzir conhecimentos sobre pessoas e eventos.

Essa concepção metodológica está sendo assumida no contexto de uma pesquisa conduzida durante 10 meses. O foco do estudo é delimitado e específico e tem por objetivo profundidade na compreensão dos dados, considerando as questões de pesquisa.

\subsection{Produção de dados}

Dentre as atividades realizadas para coleta de dados, o caso explorado neste artigo tem como base o oferecimento de um curso de extensão universitária (com duração de 20 horas) destinado a estudantes de graduação da Universidade Estadual Paulista, campus de Rio Claro. O curso foi filmado e o objetivo foi engajar os estudantes na produção de PMD visando os objetivos expostos na seção anterior. Nove estudantes de diferentes cursos de graduação participaram do curso de extensão universitária, sendo seis do curso de Matemática, um da Física, um da Ecologia e um da Pedagogia. Em algumas sessões, três estudantes de pósgraduação participaram como colaboradores, embora não formalmente matriculados.

Foram produzidas duas PMD, sendo uma de natureza cinematográfica (intitulada Harlem Math Shake) e outra de natureza musical (intitulada Séries e Provas Visuais: do Poema à Música). Após o encerramento do curso, foram também realizadas entrevistas com alguns dos participantes. Portanto, os dados de pesquisa produzidos neste estudo são:

(1) Registro das interações coletivas durante o curso de extensão;

(2) Registro de entrevistas realizada com 5 participantes do curso;

(3) Duas PMD produzidas durante o curso.

\subsection{Insights interpretativos e analíticos}

As lentes analíticas deste estudo têm como pano de fundo os seguintes aspectos:

- As categorias de Boorstin (1990) sobre cinema: voyeur, vicário e visceral. Na realidade, Scucuglia (2012) propõe uma adaptação dessas categorias para argumentar que PMD conceituais (boas PMD) devem oferecer, do ponto de vista da performance e da Educação Matemática, surpresas, sentidos, emoções e sensações matemáticas. São estas as categorias que direcionaram as ações didáticas 
voltadas à produção de PMD durante o curso de extensão oferecido, bem como o processo de interpretação das PMD produzidas.

- A multimodalidade tem um papel fundamental com relação aos processos de produção de significados matemáticos. São enfatizados os modos de comunicação oferecidos pelas mídias digitais (gestos, elementos visuais, sons, espaços, vocabulários, materiais manipuláveis, dentre outros). Nesse sentido, as tecnologias digitais condicionam o pensamento matemático, ou seja, a natureza de diferentes problemas e soluções está associada ao uso de diferentes mídias, na maneira como diversificados significados matemáticos são produzidos mediante o uso de variadas tecnologias (BORBA, VILLARREAL, 2005).

- O modelo de análise de vídeos proposto por Powell, Francisco e Maher (2004) também orientou a análise de dados. O modelo é composto por procedimentos não lineares, tais como: visualização e descrição dos dados; codificação, identificação e seleção de eventos críticos; transcrição; e composição da narrativa da pesquisa.

- Considerando a natureza e especificidades de cada PMD e as lentes interpretativoanalíticas mencionadas, primeiramente descrevo as PMD e em seguida apresento as discussões com base nas categorias emergentes neste estudo.

\subsection{Harlem Math Shake}

Harlem Math Shake é o título da primeira PMD produzida neste estudo. Foi inspirada em um hit da Internet do ano de 2013 que pode ser descrita como uma performance cinematográfica baseada em um curto trecho da música Harlem Shake (30 segundos).

Uma narrativa do tipo Harlem Shake tem um enredo que segue o seguinte padrão: Existem duas cenas principais. A câmera posicionada sempre no mesmo local (a fotografia não altera o enquadramento). Na primeira cena, aparece um ambiente social qualquer como um escritório de trabalho, por exemplo. Todos os personagens, exceto um, estão apresentando comportamentos normais àquele ambiente. Apenas um dos personagens, geralmente fantasiado, demonstra atitudes não comuns aquele ambiente. De repente, com mudança da intensidade da música, todos os personagens aparecem fazendo movimentos frenéticos, comportamentos estranhos para aquele ambiente e, geralmente, as pessoas também aparecem fantasiadas. A mudança de cena é um efeito surpresa criado com a edição de vídeo. 
Para uma melhor compreensão, o ideal é que leitor assista a PMD produzida pelos estudantes, disponível no YouTube (http://www.youtube.com/watch?v=nutcM-mDKmk) e no Math + Science Performance Festival (www.mathfest.ca).

Na primeira cena da PMD, aparece um ambiente de sala de aula no qual alunos assistem a um professor enunciar um teorema sobre a lousa. O teorema diz respeito à uma série geométrica convergente (que será discutida mais adiante). Há uma pessoa vestindo uma fantasia a de um super-herói (Wolverine) ${ }^{8}$ e dançando com um cartaz em mãos contendo uma representação de uma prova visual ao teorema, no caso, a prova apresentada em um poema investigado ao longo do curso. A prova diz respeito à convergência da série. As pessoas agem como se não notassem a presença do super-herói. E este seria o elemento estranho ao ambiente na primeira cena, característica das narrativas Harlem Shake. A Figura 2 exibe uma imagem da primeira cena da PMD. Na cena seguinte todos os participantes aparecem em lugares diferentes e comportando-se de modo estranho, cada um representando uma imagem diferente sobre o matemático. Alguns deles exploram a ideia matemática abordada na PMD. Diferentes formas de exploração da ideia matemática investigada ao longo do curso podem ser observadas no cenário na segunda cena, a qual será discutida mais adiante neste artigo.

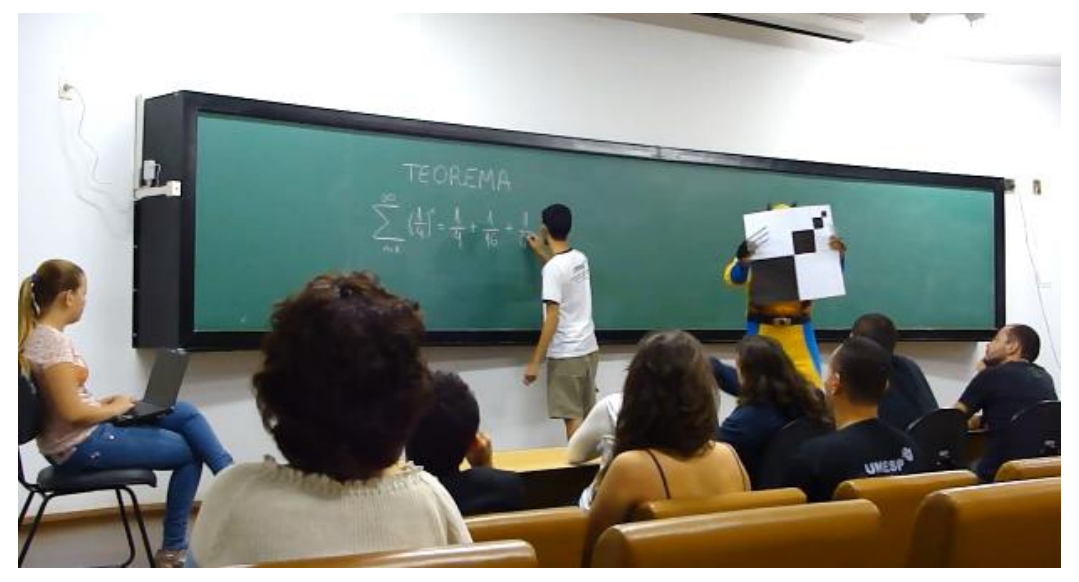

Figura 2- Imagens da PMD Harlem Math Shake (primeira cena) Fonte: http://www.youtube.com/watch?v=Qpo9QF29yos

\footnotetext{
${ }^{8}$ Wolverine é um personagem fictício, um herói de histórias em quadrinhos publicados pela Marvel Comics (...). Seu principal poder mutante é o chamado Regeneração Celular (também chamado "Fator de Cura"), dom que, além de retardar assustadoramente seu envelhecimento, lhe permite curar-se de qualquer ferimento ou envenenamento muito rapidamente. (...) Além do fator de cura, Wolverine possui sentidos super aguçados, podendo rastrear o alvo pelo cheiro (como um lobo), tendo também audição e visão superiores a de um humano normal. Possui também 6 garras retráteis de $30 \mathrm{~cm}$ (3 em cada braço) que saem de seus antebraços por meio de contração muscular, como qualquer outro movimento. Essas garras, bem como seu esqueleto, foram recobertas artificialmente com o metal Adamantium [liga metálica fictícia, considerada virtualmente indestrutível] (http://pt.wikipedia.org/wiki/Wolverine).
} 


\subsection{Séries e provas visuais: do poema à música}

A PMD musical produzida pelos estudantes também está disponível no site do Festival e no YouTube (http://www.youtube.com/watch?v=Qpo9QF29yos). A letra da música explora de forma conceitual a ideia matemática, descrevendo as formas sobre como os participantes exploraram diferentes provas visuais na investigação realizada durante o curso, além daquela originalmente declamada no poema. A melodia foi criada pelos participantes e, na narrativa, eles aparecem cantando e tocando instrumentos musicais. Diversos recursos são utilizados na edição do vídeo como recursos visuais, algébricos e simulações. Estes recursos são importantes para a compreensão matemática do que está sendo cantado. A Figura 3 exibe a letra da música.

Como é belo o poema que demonstra um teorema Uma prova visual para uma série infinita Sei que vou te convencer, demonstrar a muita gente Uma série geométrica provada convergente

Eu somo $x$, x ao quadrado, as potências naturais No poema investigado, nosso $x$ vale um quarto Pra provar que a série é um terço, Brown usou geometria

Desenhou inicialmente um quadrado unitário

Sobre a diagonal do quadrado desenhado Considere uma sequência com infinitos quadrados As diagonais se sobrepõem, os quadrados diminuem $O$ valor de cada área é reduzido em $1 / 4$

A demonstração de Brown pode parecer difícil Pra poder me convencer utilizei um artifício Só fui me convencer de que a série é um terço, Pois vi que $S$ e $1 / 2$ S é a metade do quadrado
Mas o Gregory pensou de uma forma coerente Construindo a sequência de um modo diferente Sobre a base maior posicionou cada quadrado Agora vejo uma escada que é 1/3 do quadrado

Um argumento mais algébrico eu posso apresentar, se a série é igual a $S, 4 S$ calcular Como a série é infinita $4 S$ é 1 mais $S$ $S$ então é igual a 1/3, a convergência acontece

Baseado no poema tenho uma conjectura No estudo sobre séries, convergência é importante Quando módulo de X for menor do que 1 minha gente, vejo que a série geométrica é mesmo convergente

Apresentando um poema, uma prova visual O matemático poeta declamou sua ideia A beleza do poema, verdade convencimento Um argumento visual, uma prova um desenho

Figura 3 - Letra da PMD musical (séries e prova visual) Fonte: Dados da pesquisa

\section{PMD e narrativa: a imagem da paramatemática}

PMD podem ser concebidas como narrativa de caráter matemático, artístico, digital e multimodal. O termo multimodal é utilizado neste estudo no sentido proposto por Walsh (2011) no contexto da literacia enfatizando o uso de tecnologias digitais. O texto impresso permite o trabalho apenas com um número limitado de modos de comunicação. As imagens dinâmicas e os sons, por exemplo, não são elementos explorados através do texto impresso. No entanto, as tecnologias digitais permitem fixar e moldar diversos elementos que compõem 
os diversificados modos de comunicação como: linguístico, sonoro, espacial, imagético. É nesse sentido que as tecnologias digitais possibilitam a produção de textos multimodais e os textos podem assumir um caráter narrativo através do enredo literário e performático (GADANIDIS; HOOGLAND, 2003).

De acordo com Matos (2010),

Narrativas e histórias são uma forma de pensamento, uma forma de organizar a experiência humana. Para ele, as histórias nos "fornecem modelos do mundo" (2002, p. 25). Segundo Bruner $(1990,2002)$, é por meio das narrativas que nos constituímos, que nos transformamos na pessoa que somos, ou seja, é por intermédio das histórias que nos contam e das histórias que contamos, inclusive sobre nós mesmos, que nos formamos e nos transformamos a cada dia, continuamente (MATOS, 2010, p.589).

Cruz (2006, p. 6) comenta que as narrativas representam uma possibilidade de se inserir a Matemática em um contexto de realizações humanas, "dotando-a de um significado mais dramático". Segundo a autora, narrativas são imprescindíveis para a construção de significados matemáticos, para a composição tácita de um cenário de valores e para a condução de projetos. Para Poligicchio (2011), o teatro pode ser concebido enquanto materialização da narrativa matemática. Nesse contexto, a investigação matemática e o drama são visto como meios fundamentais para o desenvolvimento imaginativo, para a abstração. Além disso, há "a afinidade estrutural entre o Teatro e a Matemática, já que ambos possuem coerência lógica na narrativa e no desenvolvimento do algoritmo, respectivamente, que conduzem à moral da história e as resoluções de problemas” (POLIGICCHIO, 2011, p. 7).

Na teorização de Bruner (2002), há uma distinção entre dois modos de pensamentos: o narrativo e o paradigmático. De acordo com Sinclair, Healy e Sales (2009, p. 442), para Bruner, "o pensamento paradigmático é lógico, dedutivo e atemporal; se baseia em afirmações de certeza e raciocínio justificado. Em contraste, o modo narrativo se esforça para colocar os 'milagres sem tempo' em particularidades da experiência e dando à própria experiência um tempo e um local".

Tanto o modo narrativo quanto o paradigmático têm papéis fundamentais na construção e [organização] do conhecimento, mas eles têm motivações diferentes: enquanto o paradigmático está preocupado com o que é, dadas as limitações do sistema em questão, e com a identificação e prova de generalidades que caracterizam objetos e relações no sistema, à narrativa se concentra em atividades particulares desses objetos, como eles são jogados no tempo, sobre o que poderia estar por trás dos eventos em questão e sobre a forma como eles se assemelham ou nos lembram de outras coisas que conhecemos (SINCLAIR; HEALY; SALES, 2009, p.443).

Nesse sentido, é importante destacar que PMD combinam esses dois modos de pensamento. De acordo com Doxiadis (2003), a noção de paramatemática diz respeito ao 
hibridismo entre os modos de pensamentos narrativo e paradigmático no ensino de Matemática baseado na construção de narrativas.

A narrativa matemática deve entrar no currículo escolar, tanto a nível fundamental como médio. O objetivo é: (a) aumentar o apelo a disciplina; (b) oferecer à matemática um senso de relevância social, histórica e intelectual e um lugar em nossa cultura; (c) oferecer aos estudantes um melhor sentido sobre o escopo da área, além das necessárias técnicas matemáticas limitadas que podem ser ensinadas dentro das limitações do sistema escolar (DOXIADIS, 2003, p. 20).

A ideia matemática explorada nas duas PMD produzidas neste estudo foi uma prova visual para uma série infinita convergente. Esta ideia, que abre uma discussão sobre convencimento e verdade em Filosofia da Matemática, foi explorada a partir de um poema de autoria de James Brown, apresentado por Zwicky (2000) (ver Figura 4).

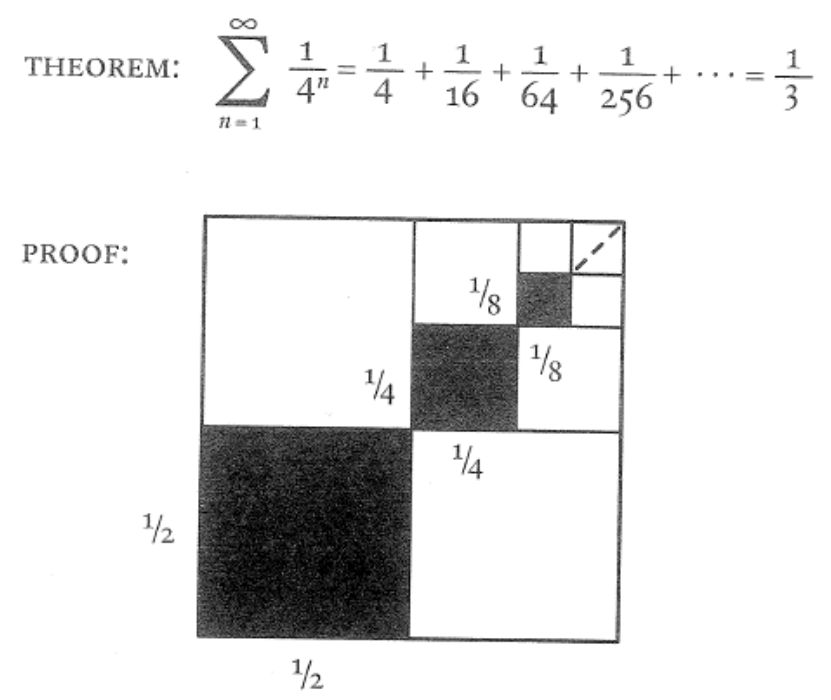

Figura 4 - O poema apresentado por Zwicky (2000)

Ao longo da investigação do poema realizada durante o curso, os estudantes de graduação propuseram formas diferenciadas para se provar (visualmente) o teorema. Essas formas de investigação matemática estão presentes de forma artística nas narrativas digitais produzidas pelos estudantes, foco deste artigo. Embora o poema tenha sido a ideia matemática investigada em maior profundidade durante curso, eu havia proposto aos estudantes a exploração de três diferentes provas visuais para séries geométricas convergentes, todas elas apresentadas no livro de Zwicky (2000).

De forma dialógica, os estudantes discutiram o fato de que todas as ideias tinham grande potencial para oferecer uma surpresa matemática à audiência, o que é fundamental 
para a produção de um PMD conceitual (WATSON; MASON, 2007). Diferentes formas de provas visuais investigadas pelos estudantes estão presentes em ambas as narrativas.

As provas visuais contribuem com a desconstrução ou superação da imagem da Matemática enquanto formalista e absolutista. A noção de verdade matemática, explorada principalmente pela Filosofia da Matemática, evidencia em tendências de natureza falibilista os aspectos visuais na investigação matemática, não somente como auxiliadores na trajetória heurística, mas como elementos fundamentais que compõe $\mathrm{o}$ convencimento $\mathrm{e}$ a argumentação matemática na busca por verdades (HANNA, 2002).

Noções falibilistas associadas a paramatemática intensificam o aspecto subversivo às tendências formalistas. A PMD musical explora com profundidade várias abordagens visuais e múltiplas representações dos objetos explorados (ver Figura 5).

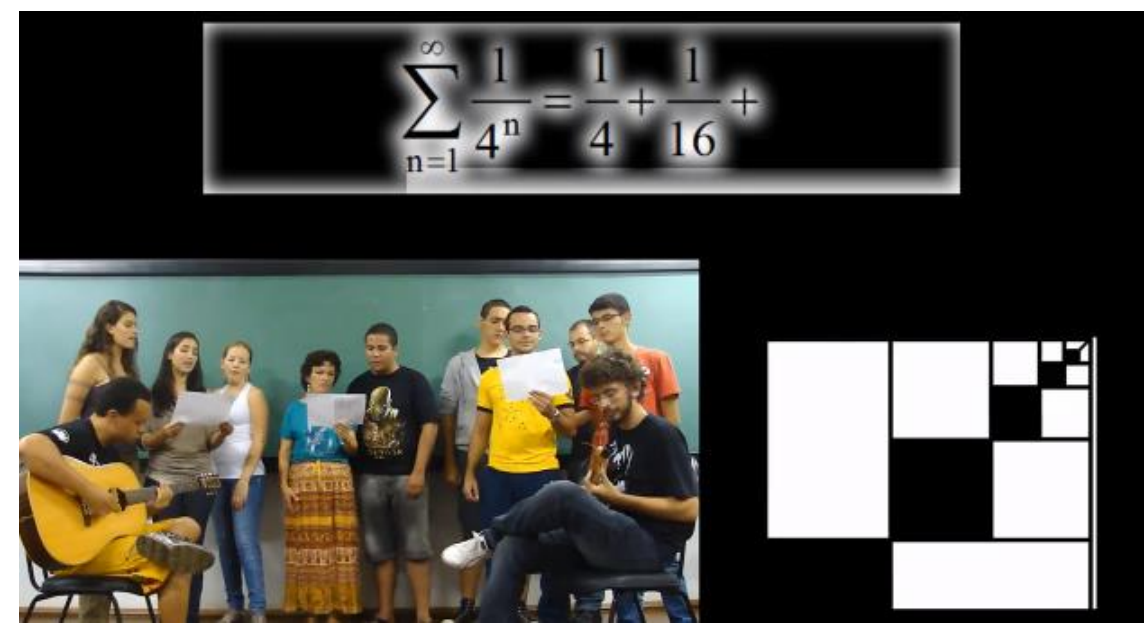

Figura 5 - Imagem da PMD que destaca o aspecto da visualização Fonte: http://www.youtube.com/watch?v=Qpo9QF29yos

\section{Matemáticos: múltiplas imagens}

O processo de construção das imagens ocorreu durante o curso de forma coletiva. Nós negociamos formas de elencar colaborativamente 11 imagens que seriam exploradas na performance Harlem Shake. Uma a ser explorada e interpretada por cada participante ${ }^{9}$. Tendo definidas estas imagens ou papéis, cada participante assumiu a reponsabilidade por atuar no papel de uma delas e construir elementos que caracterizassem seu personagem. Na performance musical, eu propus as duas imagens exploradas, pois elas emergiram de minha

\footnotetext{
${ }^{9}$ Havia nove estudantes matriculados regularmente no curso. Nesse dia, dois estudantes de graduação não estavam presentes e três estudantes de pós-graduação participaram como colaboradores, como ouvintes, e atuaram na performance. Eu também atuei na performance, totalizando assim 11 participantes na narrativa.
} 
interpretação sobre aspectos pedagógicos significativos ocorridos no curso com relação a investigação matemática dos estudantes sobre a prova visual.

O processo de construção das imagens esteve baseado nos resultados da pesquisa de Picker e Berry (2000), que propõem sete categorias para identificar semelhanças entre os desenhos de matemáticos feitos por estudantes de diferentes países. As categorias são:

(1) Matemática como coerção: os estudantes veem os matemáticos como professores que usam intimidação, violência ou ameaças em sala de aula. Este foi um tema completamente inesperado que surgiu a partir dos desenhos,

(2) Os matemáticos como "tolos": matemáticos foram retratados como desprovidos de senso comum, senso de moda, ou habilidades computacionais,

(3) O matemático exausto: matemáticos foram descritos como impacientes e extremamente tensos e cansados,

(4) Matemáticos que não sabem ensinar: uma sala de aula é desenhada na qual o matemático não é capaz de liderar as aulas, ou não conhece o conteúdo,

(5) Menosprezo dos matemáticos: os matemáticos são representados como sendo muito inteligentes, mas frios e arrogantes;

(6) O efeito Einstein: desenhos com uma referência a Albert Einstein. Normalmente, essas imagens são influenciadas pela mídia, incluindo livros e desenhos animados,

(7) Matemáticos com poderes especiais: que inclui magia e poções matemáticas. Algo extraordinário é necessário para a atividade matemática.

Foram 11 as imagens de matemáticos exploradas pelos estudantes na PMD Harlem Shake: o professor tradicional e o super-herói, vistos já na primeira cena. Na segunda cena: o músico roqueiro, o nerd, o monstro, o louco, o que usa computadores, o que usa livros, o poeta, o Einstein e o professor sarcástico (ver Figura 6). 


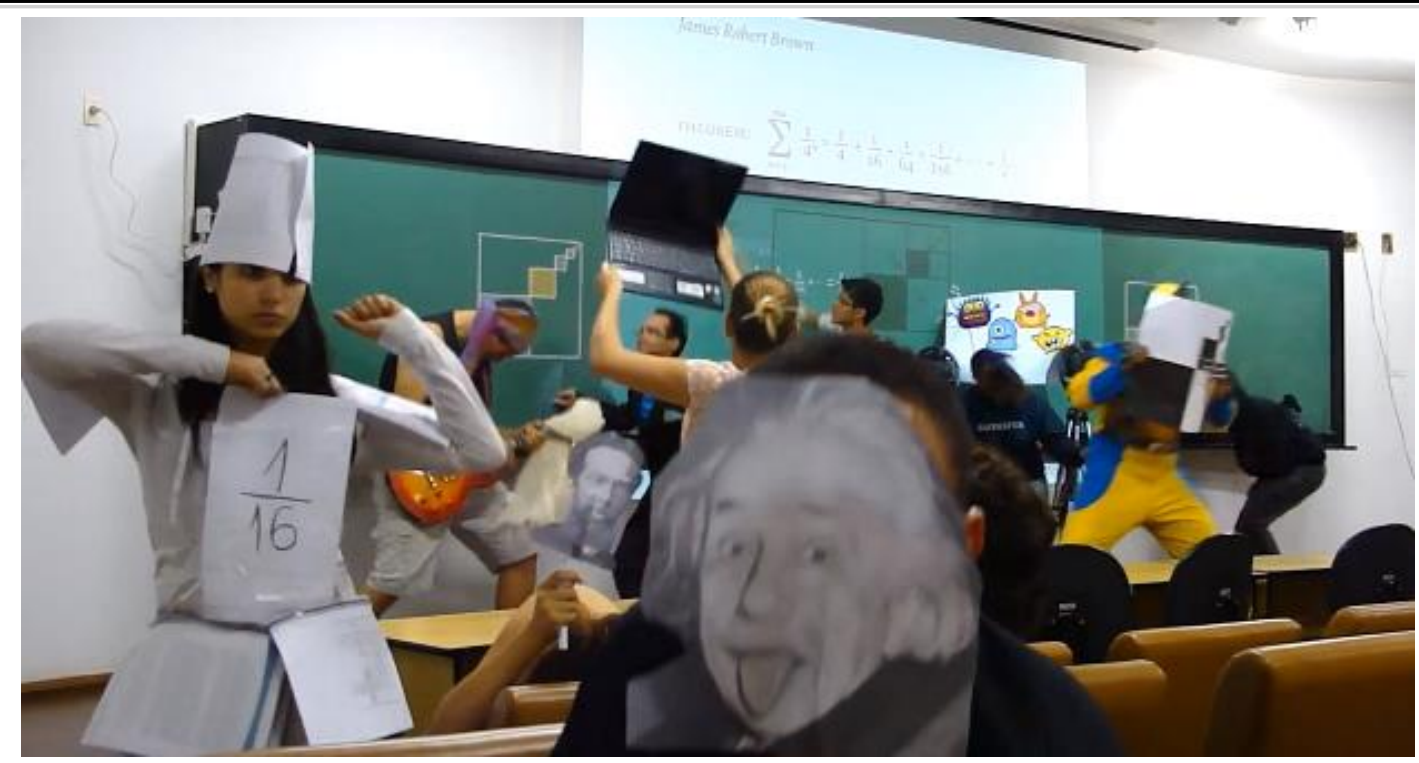

Figura 6 - As imagens dos matemáticos na PMD Harlem Math Shake

As principais imagens exploradas na narrativa musical foram o matemático enquanto poeta e o matemático enquanto o estudante que conjectura múltiplas soluções a um problema. Portanto, durante o curso, os estudantes exploraram 12 diferentes imagens sobre matemáticos ao buscarem produzir narrativas multimodais envolvendo performance artística.

Além disso, na construção das PMD foram levadas em consideração as questões diretrizes propostas por Rock e Shaw (2000): (1) Em que local os matemáticos trabalham? (2) Que tipos de problemas os matemáticos resolvem? (3) Quais as ferramentas ou instrumentos que os matemáticos usam? Na PMD Harlem Shake, a sala de aula é o cenário da performance. Lousa, computadores e livros foram os principais instrumentos utilizados e uma prova visual para uma série geométrica convergente fora o problema explorado. Embora tenha sido enfatizado que todos os personagens deveriam buscar ações que estivessem relacionadas a algo sobre a ideia matemática, isso não ocorreu necessariamente. Mas podem ser notadas representações sobre a lousa, o cartaz nas mãos do super-herói e as ações realizadas pelo matemático que usa livros. Esse personagem mostra de forma criativa os termos que formam a série explorada.

Algumas das imagens exploradas no Harlem Math Shake representam as imagens identificadas por Picker e Berry (2000). Estas imagens incluem visões estereotipadas e alternativas sobre os matemáticos. Durante o curso de extensão, os estudantes criaram coletivamente um conjunto de identidades para os matemáticos. Eles quiseram comunicar tanto os estereótipos atribuídos pela sociedade na opinião deles como também imagens não 
comuns, que foram possíveis de serem pensadas com a realização de um curso sobre PMD, na qual o matemático pôde ser visto também como músico, como poeta e estudante.

Na narrativa musical, o palco é o cenário da performance. A imagem do matemático enquanto poeta e enquanto estudante que propõe múltiplas soluções a um problema pode ser vista como uma imagem alternativa aos estereótipos (negativos) geralmente atribuídos aos matemáticos quando exploramos suas imagens públicas.

\title{
7.1 Matemáticos performáticos
}

O processo de produção de PMD está relacionado ao processo de construção de identidades realizado por estudantes através da atividade performática. Gadanidis, Hughes e Borba (2008) argumentam que, ao produzir uma PMD, existe uma relação entre narrativa e identidade na qual os estudantes podem ser vistos como performance mathematicians.

É importante desconstruir concepções singulares e elitistas que consideram como matemático apenas o indivíduo com titulação de doutor em Matemática. Wood, Petocz e Reid (2012) dão um passo importante ao investigarem o processo de tornar-se matemático ao cursar a graduação em Matemática. Gadanidis (2012) vai além e traz o processo de PMD como um meio para que as crianças tenham a imagem delas mesmas como matemáticos.

De acordo com Denzin (2003), o papel das mídias (como as tecnologias usadas para produzir PMD) é fundamental na construção de identidades.

\begin{abstract}
Os ingredientes do eu pós-moderno são moldados pelas mídias. O eu pós-moderno tem se tornado um signo de si mesmo. De um lado, uma reflexão dramatúrgica dupla ancorada nas representações midiáticas. De outro, a vida cotidiana. Estas identidades culturais são filtradas através dos problemas pessoais e das experiências emocionais dos indivíduos em interações do dia-a-dia. Estes problemas existenciais reconectam os temas da cultura dominante da era pós-moderna. As mídias eletrônicas e as novas tecnologias da informação transformam a vida diária em um espetáculo teatral onde os dramas que envolvem as performances decisivas de crises existenciais são promulgados. Isto cria uma nova videocy existencial, uma linguagem de crises codificada em termos eletrônico, midiáticos (DENZIN, 2003, p. 60).
\end{abstract}

Simplificando ao extremo, quando um indivíduo produz uma narrativa, pensa-se sobre as múltiplas formas (provisórias) sobre como expor o Eu (Self) ao(s) outro(s), ao mundo. Os outros são amalgamados complexos de componentes culturais, históricos e sociais, materializados pelo ser biológico racional, linguístico. É nessa reciprocidade representativa (simbólica) entre os eus e os outros que nossas identidades se formam. Os eus, que se 
constituem necessariamente através da linguagem (falas, ações, textos e/ou das narrativas, enunciações) são espelhos de todos aqueles componentes que constituem o(s) outro(s).

Bruner (1976, p. 71) afirma que "jamais haverá um self independente da existência cultural-histórica de um indivíduo". "O Self é uma construção, um resultado de ação e simbolização (...), como um texto sobre como alguém está situado em relação aos outros e em relação ao mundo (...). Ele é composto de expectativas, sentimentos de estima e poder, etc. (BRUNER, 1976, p. 136). Complementando, Matos (2010) comenta que:

\begin{abstract}
Para Bruner, nosso "Eu", nossa identidade, nada mais é que uma construção, um conceito criado pela reflexão, da mesma forma que construímos outros conceitos. Além disso, como vimos, nosso "Eu" é constantemente criado e recriado por meio de nossas narrativas, nossas histórias de vida (Bruner, 2002). Bruner ressalta, ainda, que nossa identidade é "profundamente relacional", isto é, nosso "Eu" é também constituído pelo "outro" por meio de nossas (inter)relações sociais. Segundo ele, por meio da nossa capacidade de narrar, produzimos nosso "Eu", "que nos une aos outros" e que reflete nossa cultura dialeticamente (MATOS, 2010, p. 590).
\end{abstract}

Assim, no contexto deste estudo, no qual narrativas multimodais foram produzidas através da noção de PMD, a audiência é fundamental na construção do eu performático. As narrativas estão publicadas no YouTube e no Festival, podendo ser acessadas por qualquer pessoa. A narrativa multimodal, a PMD enquanto texto digital, é constituída simbolicamente a partir de questionamentos do tipo: Quem irá assistir a minha performance na Internet? Quem são os outros que assistirão a minha performance online? Como devo me expor diante dos outros? Como devo comunicar de forma clara minhas ideias matemáticas? O que os outros pensarão sobre o eu matemático ao assistirem minha PMD?

Dois níveis de indenidades podem ser discutidos no processo de produção de PMD.

- Há uma dimensão presencial. Muitas PMD são conduzidas em salas de aula, por exemplo, na presença de estudantes e professores. Em vários casos, embora não possam ser vistos, é possível ouvir aplausos ao final das performances. Há ainda aquelas performances conduzidas em teatros ou em ambientes fora da sala de aula.

- Há uma dimensão online. Por serem textos digitais, as narrativas multimodais tornamse artefatos públicos, que podem ser acessados no ciberespaço, em particular no YouTube ou Festival (www.mathfest.ca). Então, a produção de uma PMD pode ser interpretada como um processo de construção de identidades online, no sentido proposto por Rosa (2008). Ao produzirem uma PMD, os estudantes têm ciência de que a narrativa digital estará disponível online. Então, o eu performático em PMD é 
também moldado pelo modo como os estudantes concebem a natureza da audiência online de suas performances digitais (SCUCUGLIA, 2012).

O fato das PMD serem de domínio público no ciberespaço é também importante para trazer a Matemática dos estudantes para além da sala de aula. Gadanidis e Geiger (2010, p. 102) têm se referido ao Festival de Performances Matemáticas como "um exemplo que ajuda a trazer as ideias matemáticas dos alunos em fóruns públicos onde possam ser compartilhadas e criticadas, oferecendo oportunidade para o desenvolvimento contínuo de conhecimento e compreensão dentro de uma comunidade de apoio dos alunos”.

Gadanidis e Geiger (2010, p. 101) também comentam que o Festival “oferece um vislumbre de como a colaboração na aprendizagem matemática pode ser estendida para incluir a performance de matemática, ou talvez como a colaboração em um ambiente de mídia rico digitalmente pode ser compreendido como performance colaborativa". Em termos de reconhecimento, comento que as PMD produzidas nesta pesquisa foram premiadas no Math + Science Performance Festival (temporada 2012-2013) ${ }^{10}$ e todos os participantes das PMD foram homenageados com medalhas oferecidas pelo Fields Institute (Universidade de Toronto), pela Western University e pela ESSO Imperial Oil.

\section{Insights finais}

Scucuglia (2012) propõe que PMD conceituais (boas PMD) devem apresentar a audiência surpresas, sentidos, emoções e sensações matemáticas. Com base nesse critério, construído a partir de perspectivas sobre cinema (BOORSTIN, 1990), argumento que produção de PMD conceituais é um evento raro, embora a natureza da ideia matemática explorada no curso - provas visuais - seja considerada conceitual. A busca por clareza e profundidade com relação ao sentido matemático em performances musicais geralmente exige a exploração de recursos visuais. Isso foi necessário para a produção da narrativa musical apresentada neste estudo.

De forma criativa, os estudantes tendem a propor a produção de PMD com a utilização de recursos e efeitos visuais sofisticados. Contudo, os softwares utilizados não possibilitam tal produção. Para sua realização seria necessária a utilização de software e computadores de alta performance. Ao se produzir uma PMD (em um ambiente multimodal de aprendizagem) é

\footnotetext{
${ }^{10}$ http://www.mathfest.ca/mpf2013/index.html
} 
fundamental que o professor, pesquisador ou artista, enquanto coordenador ou diretor busque um ambiente dialógico e colaborativo para a tomada de decisões e negociação de significados.

A produção de PMD em períodos curtos de tempo em cenários nos quais os participantes estão tendo um primeiro contato com PMD exige a tomada de decisões e ações por parte do professor. Por exemplo: com relação a ideia matemática a ser explorada, a criação do enredo da performance, os aspectos técnicos sobre filmagem e execução dos eventos artísticos, edição de vídeo, produção da narrativa, etc.

Houve coletividade e colaboração na produção de PMD neste estudo, mas alguns aspectos devem ser aprimorados para que os participantes tenham um envolvimento ainda mais profundo, dentro de uma noção de inteligência coletiva (LÉVY, 2000).

Os estudantes tendem a explorar mais seus sentimentos com relação ao ensino e aprendizagem da Matemática, a eventos e atitudes que ocorrem em sala de aula, ao invés de explorarem a ideia matemática em si. O papel de orientação do professor é fundamental para que a performance explore fundamentalmente uma ideia matemática e o enredo da história ofereça surpresa, sentido, emoção e sensação matemática.

Alguns estereótipos sobre a Matemática e sobre os matemáticos já faziam parte da visão dos estudantes: autoritário, frio, monstro, herói, mágico. Na primeira sessão de cada curso, os estudantes desenharam um matemático em seu local de trabalho. Os estudantes de graduação viam os matemáticos como professores, mas também como pesquisadores. Mas eles consideraram que as pessoas em geral veem os matemáticos essencialmente como professores, com características negativas como estressados, arrogantes, sarcásticos e autoritários. Estes resultados vão em direção aos mesmos resultados apontados por Picker e Berry (2000). Entre os graduandos, a imagem do matemático como super-herói foi proposta diante da imagem da Matemática como um monstro a ser derrotado pelo super-herói. $\mathrm{O}$ matemático foi visto também como um mágico. Por não produzirem sentido matemático a partir do que o professor comunica em sala de aula, estudantes veem operações aritméticas e algébricas como passes de mágica.

Os estudantes tomaram conhecimento de imagens alternativas sobre a Matemática e sobre os matemáticos durante o processo dialógico que ocorreu nos cursos, principalmente o matemático como poeta e músico. Contudo, ao produzirem uma PMD, eles buscaram exibir tanto algumas dessas imagens alternativas quanto os estereótipos que dizem respeito a imagem pública dos matemáticos. A busca foi pela diversidade de papéis artísticos e imagens. 
Com relação à imagem da Matemática, por buscar-se a produção de uma PMD conceitual durante os cursos, foi explorada nuances de surpresa matemática através de uma prova visual, o que pode oferecer modos de se ver a matemática como uma atividade múltipla e diversa e não como absoluta, apenas sobre o certo ou errado. Contudo, tende-se a exibir em algum momento o ensino de Matemática como tradicional.

\section{Agradecimentos}

Ao Conselho Nacional de Desenvolvimento Científico e Tecnológico (CNPq), pelo financiamento a pesquisa relatada neste artigo (Processo: 158000/2012-9).

Ao coordenador do Grupo de Pesquisa em Informática, outras Mídias e Educação Matemática (GPIMEM), UNESP Rio Claro, Dr. Marcelo C. Borba, pela orientação e colaboração na pesquisa.

Aos integrantes do GPIMEM pela revisão e sugestões em versões do artigo, principalmente, Hannah Lacerda.

Em especial, à Alana Fuzaro de Barros Rodrigues pela revisão do artigo.

\section{Referências}

ADAMS, D. Hichhiker's guide to de galaxy. New York: Del Books/Random House, 2005.

BOORSTIN, J. The Hollywood Eye. What makes movies work. New York: Cornelia \& Michael Bessie Books, 1990.

BORBA, M.; SKOVSMOSE, O. A ideologia da certeza em Educação Matemática. In: SKOVSMOSE, O. (Org.). Educação Matemática Crítica. Campinas: Editora Papirus, 2001, p. 127148.

BORBA, M. C.; VILLARREAL, M. E. Humans-with-media and the reorganization of mathematical thinking. New York: Springer, 2005.

BRUNER, J. Uma nova teoria de aprendizagem. Rio De Janeiro: Bloch Editores S.A, 1976.

BRUNER, J. Actual minds, possible worlds. Cambridge, Massachusetts: Harvard University Press, 1986.

BRUNER, J. Acts of meaning. Cambridge. London: Harvard University Press, 1990.

BRUNER, J. Making stories: Law, literature, life. Cambridge, MA: Harvard University Press, 2002. 
CRUZ, M. O. Construção da identidade pessoal e do conhecimento: a narrativa no ensino de matemática. 2006. 147 f. Dissertação (Mestrado em Educação). Faculdade de Educação Universidade de São Paulo (USP), São Paulo, 2006.

DENZIN, N. Performance ethnography: Critical pedagogy and the politics of culture. Thousand Oaks, CA: Sage, 2003.

DOXIADIS, A. Embedding mathematics in the soul: narrative as a force in mathematics education, Opening address to the Third Mediterranean Conference of Mathematics Education, Athens, Greece.2003. Disponível em: <http://www.apostolosdoxiadis.com/files/essays/embeddingmath.pdf, $>$. Acesso em: 16 mar. 2010.

FRANK, M. L. What Myths about mathematics are held and conveyed by teachers? Arithmetic Teacher, Washington, v. 37, n. 5, p. 10-12, jan. 1990.

FURINGHETTI, F. Images of Mathematics Outside the Community of Mathematicians: Evidence and Explanations. For the Learning of Mathematics, Fredericton (Canadá), v.12, n.2, p.33-38, maio/ago. 1993.

GADANIDIS, G.; HOOGLAND, C. The aesthetic in mathematics as story. Canadian Journal of Science, Mathematics and Technology Education. Toronto, v. 3, n. 4, p. 487-498, out. 2003.

GADANIDIS, G.; BORBA, M. C. Our lives as performance mathematicians. For the Learning of Mathematics, Fredericton (Canadá), v. 28, n. 1, p. 44-51, jan../abril. 2008.

GADANIDIS, G.; SCUCUGLIA, R. Windows into elementary mathematics: alternate mathematics images of mathematics and mathematicians, Acta Scientiae, Canoas, v. 12, n. 1, p. 24-42, jan./jun. 2010 .

GADANIDIS, G.; GEIGER, V. A social perspective on technology enhanced mathematical learning from collaboration to performance. ZDM - The International Journal on Mathematics Education, Berlin, v. 42, n. 1, p. 91-104, fev. 2010.

GADANIDIS, G. Why can't I be a mathematician? For the Learning of Mathematics, Fredericton (Canadá), v. 32, n. 2, p. 20-26, maio/ago. 2012.

HANNA, G. Proof, explanation and exploration: an overview. Educational Studies in Mathematics, Dordrecht, Holanda, v. 44, n. 1-2, p. 5-23, dez. 2000.

LEVY, P. Cibercultura. Rio de Janeiro, Brazil: Editora 34, 2000.

LIM, C. S. Public Images of Mathematics. 1999. 365 f. Tese (Doutorado em Educação). University of Exeter: United Kingdom, 1999. Disponível em<http://people.exeter. ac.uk/PErnest/pome15/lim_chap_sam.pdf>. Acesso em: 26 mar. 2010.

LIM, C. S.; ERNEST, P. Public Images of Mathematics. Philosophy of Mathematics Education, v.11, 1999. Disponível em <http://www.people.ex.ac.uk/ PErnest/pome11/art6.htm>. Acesso em: 26 mar. 2001.

MATOS, A.M.A. Narrativas, identidades e ação política na pós-modernidade. Educação\&Sociedade. Campinas, v. 3, n. 111, p. 587-602, abril/jun. 2010. 
PICKER, S.; BERRY, J. Investigating Pupils Images of Mathematicians. Educational Studies in Mathematics, Dordrecht, v. 43, n. 1, p. 65-94, jul. 2000.

PICKER, S.; BERRY, J. Your Students' Images of Mathematicians and Mathematics. Mathematics Teaching in the Middle School, Washington, v.7, n.4, p.202-208, dez. 2001.

POLIGICCHIO, A. G. Teatro: A Materialização da Narrativa Matemática. 2011. 148 f.

Dissertação (Mestrado em Educação) - Faculdade de Educação, Universidade de São Paulo, São Paulo. 2011.

POWELL, A. B.; FRANCISCO, J.; MAHER, C. Uma abordagem à análise de dados de vídeo para investigar o desenvolvimento das ideias matemáticas e do raciocínio de estudantes. Boletim de Educação Matemática, Rio Claro, v. 21, n. 1, p.81-140, jan./jun. 2004.

RENSAA, R. J. The Image of a Mathematician. Philosophy of Mathematics Education, Exeter, v. 19, n 1, dez. 2006.

ROCK, D.; SHAW, J.M. Exploring Children's Thinking about Mathematicians and Their Work. Teaching Children Mathematics, Washington, v. 6, n. 9, p. 550-555, maio. 2000.

ROSA, M. A Construção de identidades online por meio do Role Playing Game: relações com o ensino e aprendizagem de matemática em um curso à distância. 2008. 263 f. Tese (Doutorado em Educação Matemática) - Instituto de Geociências e Ciências Exatas, Universidade Estadual Paulista, Rio Claro, SP, 2008.

SCUCUGLIA, R. R. S. On the nature of students' digital mathematical performances: When elementary school students produce mathematical multimodal artistic narratives. Germany: Verlag LAP Lambert Acedemic Publishing, 2012.

SCUCUGLIA, R. R. S.; BORBA, M. C.; GADANIDIS, G. Cedo ou tarde Matemática: uma performance matemática digital criada por estudantes do ensino fundamental. REMATEC. Revista de Matemática, Ensino e Cultura, Natal, v. 7, n. 11, p. 39-64, jul./dez. 2012.

SCUCUGLIA, R. R. S., GADANIDIS, G. Performance Matemática: Tecnologias Digitais e Artes da Escola Pública de Ensino Fundamental. In: Marcelo C. B.; Aparecida C. Tecnologias Digitais e Educação Matemática. 1 ed. São Paulo: Editora Livraria da Física, 2013, v.1, p. 325-363.

SINCLAIR, N.; HEALY, L.; SALES, C. O. R. Time for telling stories: narrative thinking with dynamic geometry. ZDM - The International Journal on Mathematics Education, Berlin, v. 41, n. 4, p. 441-452, mai. 2009.

SPANGLER, D. A. Assessing Students' Beliefs about Mathematics. Mathematics Educator, v.3, n.1, p.19-23, 1992. Disponível em: <http://math.coe.uga.edu/tme/v03n1/5spangler.pdf >. Acesso em: 26 mar. 2010.

STAKE, R. Case studies. In: DENZIN N. K.; LINCOLN Y. S. (Ed.). Strategies of qualitative inquiry. 2 Ed. Thousand Oaks, CA: Sage, 2003. p. 134-164.

YIN, R. K. Case study methods. In: GREEN J. L.; CAMILLI G.; MOORE P. B. (Ed.). Handbook of complementary methods in educational research. Mahwah, NJ: Lawrence Erlbaum Associates, 2006. p. 279-298 
WATSON, A.; MASON, J. Surprise and Inspiration. Mathematics teaching incorporating micromath. Derby, v. 200, n. 1.p. 4-7, jan. 2007.

WALSH, M. Multimodal Literacy: Researching Classroom Practice. Sydney: e:lit, Primary Teachers Association of Australia, 2011.

WOOD, L.; PETOCZ, P.; REID, A. Becoming a Mathematician: An International Perspective. Dordrecht: Springer, 2012.

ZWICKY, J. Wisdom \& Metaphor. Kentville, NS: Gaspereau Press, 2000.

Submetido em Agosto de 2013. Aprovado em Janeiro de 2014. 